\title{
PENGARUH KOMPOSISI SERAT TERHADAP KEKUATAN IMPAK KOMPOSIT YANG DIPERKUAT SERAT BAMBU
}

\author{
Fachri Arif Wahyudi ${ }^{1 *}$, Lukito Dwi Yuono ${ }^{2}$ \\ Jurusan Teknik Mesin Universitas Muhammadiyah Metro \\ JI.Ki Hajar Dewantara No.166 Kota Metro Lampung 34111, Indonesia ${ }^{1,2)}$ \\ fachriarifwahyudin@yahoo.com ${ }^{1}$, lukitody1@gmail.com ${ }^{2}$
}

\begin{abstract}
Abstrak
Komposit merupakan material yang terbentuk dari kombinasi dua atau lebih, sehingga dihasilkan material komposit yang mempunyai sifat mekanik dan karekteristik yang berbeda. Salah satu contoh Bambu merupakan tanaman sebangsa rumput yang banyak tumbuh dinegara kita. Tanaman ini dapat tumbuh didaerah beriklim panas maupun dingin. Kebanyakan didareah pedesaan tanaman bambu dibiarkan tumbuh liar, akan tetapi walaupun tidak mendapatkan perawatan, bambu dapat tumbuh dengan baik. Serat bambu berpotensi menjadi penguat dalam komposit. Tujuan dari penelitian ini adalah Mengetahui pengaruh fraksi volume komposit yang diperkuat serat bambu terhadap kekuatan impak, dan mengetahui struktur penampang patahan dengan pengamatan uji SEM. Bahan penelitian adalah serat bambu dengan menggunakan serat bambu apus, unsaturated resin polyester YUKALAC 157 BQTN=EX. Komposit dibuat dengan cara manual dengan komposisi serat 5\%, 10\%, 15\% dan 20\%. Pembuatan dilakukan dilaboratorium teknik mesin fakultas teknik universitas muhammadiyah metro dan pengujian mekanik dilakukan di B4T Bandung. Hasil pengujian didapat bahwa, hasil kekuatan impak dengan fraksi serat 5\%, 10\%, 15\% dan $20 \%$ sebesar $3,28 \mathrm{~kJ} / \mathrm{m}^{2}, 12,64 \mathrm{~kJ} / \mathrm{m}^{2}, 18,77 \mathrm{~kJ} / \mathrm{m}^{2}$, dan $27,44 \mathrm{~kJ} / \mathrm{m}^{2}$. Pada penampang patahan komposit masih terlihat terjadi kegagalan poll-out yang disebabkan bonding (daya ikat) antara serat dan matrik yang kurang sempurna sehingga pada saat terjadi pengujian, serat terlepas dari matrik. Pada spesimen uji impak, dijumpai adanya matrik cracking, yaitu retaknya matrik akibat matrik bersifat getas. Hal ini perlu menjadi perhatian karena jika retakan yang terjadi melebihi batas dapat menyebapkan debonding.
\end{abstract}

Kata kunci : Komposit, Serat Bambu, Ketangguhan, Impak.

\section{Pendahuluan}

Bambu merupakan tanaman yang mudah ditemukan didaerah yang tropis, hal ini didasarkan pada survei stastistik oleh ilmuwan yang bernama Ucimura (1980) yang menyatakan $80 \%$ bambu dunia berada dikawasan Asia Selatan dan Asia Tenggara dan jenis bambu dari genus Bambusa adalah paling banyak dan mudah ditemukan didaerah tropis [1]. Bambu yang memiliki bentuk batang yang terdiri dari serat-serat panjang dan beruas-ruas memungkinkan bambu berdiri tegak. Serat alam khususnya bambu yang berlimbah di Indonesia sangat berpotensi untuk dikembangkan sebagai bahan teknik dengan melakukan rekayasa material komposit berpenguat serat bambu. Sampai saat ini serat bambu belum dimanfaatkan secara optimal bagi kesejahteraan masyarakat Indonesia dalam membuat berbagai produk manufaktur. Serat alami mempunyai beberapa keunggulan dibandingkan dengan serat sintetis. Keunggulan dari serat alami adalah nonabrasive, densitas rendah, harga lebih murah, ramah lingkungan, dan tidak membahayakan kesehatan.

Berbagai jenis bambu dengan kualitas yang baik tumbuh subur di berbagai daerah di Indonesia. Serat bambu mempunyai potensi yang baik untuk dikembangkan menjadi bahan biokomposit yang kuat, murah, ramah lingkungan, dan dapat didaur ulang. 
Pemilihan serat bambu sebagai bahan penelitian dengan mempertimbangkan potensi serat bambu di Indonesia yang berlimpah dan belum termanfaatkan secara baik. Para peneliti menggunakan komposit serat alam sebagai produk unggulan sesuai dengan keistimewaannya. Walaupun tak sepenuhnya menggeser serat sintetis, pemanfaatan serat alam yang ramah lingkungan merupakan langkah bijak untuk menyelamatkan kelestarian lingkungan.

Melihat dari potensi tersedianya bahan baku, maka penelitian ini di arahkan untuk pemanfaatan serat bambu sebagai bahan penguat material komposit. Penggunaan serat alami sebagai filler dalam komposit dimaksudkan untuk lebih menurunkan biaya bahan baku dan peningkatan nilai salah satu produk [2]. Fungsi serat secara umum pada komposit adalah untuk memperkuat, sehingga akan diperoleh produk yang lebih kuat dan kokoh. Bahan komposit berpenguat serat banyak diaplikasikan untuk alat-alat yang membutuhkan material yang mempunyai perbedaan sifat dasar, yaitu kuat sekaligus ringan. Perkembangan teknologi komposit belakangan ini mulai beralih dari komposit dengan material penyusun sintetis menuju ke bahan komposit dengan material penyusun dari bahan alami, baik material untuk matriks maupun dengan serat (penguat) itu sendiri.

Kekuatan tarik serat bambu yang mengacu pada setandar ASTM D 638M-84, telah dibuat sample komposit polimer dengan penguat serat bambu dan serat gelas dengan fraksi volume masing-masing yaitu 2,5\%,5\%, $7,5 \%, 10 \%$ dan $12,5 \%$ kemudian diperoleh nilai karakteristik yang mendekati ideal pada masing-masing fraksi volume $2,5 \%$, dan memiliki kekuatan tarik sebesar 38,57 Mpa [1]. Dan juga dalam penelitian (Pramuko, 2011) Kekuatan impak dari komposit yang diperkuat serat eceng gondok, dengan panjang serat $25 \mathrm{~mm}, 50 \mathrm{~mm}, 100 \mathrm{~mm}$ dengan fraksi volume $80 \%$ resin dan $20 \%$ serat didapat kekuatan impak yang paling rendah terdapat pada $100 \mathrm{~mm}$ yaitu $0,0010836 \mathrm{~J} / \mathrm{mm}^{2}$, dan kekuatan impak yang paling tinggi terdapat pada $25 \mathrm{~mm}$ yaitu $0,002344 \mathrm{~J} / \mathrm{mm}^{2}$.

Ada pun dalam penelitin komposit yang diperkuat serat bambu ini, yang ingin diketahui adalah harga impak suatu bahan yang diakibatkan oleh gaya kejut pada bahan uji dengan menggunakan mesin uji bentur (impact). Setelah diketahi harga atau gaya pada uji impact, dilakukanlah pengujian selanjutnya yaitu uji SEM (Scaning Electron Microscope) untuk mengetahui jenis patahan yang terjadi pada komposit tersebut.

\section{Tinjauan Teoritis}

Bambu tumbuh secara bergerombol membentuk rumpun, tunas-tunas mudanya keluar dari rimpang dan membentuk tanaman baru. Tanaman baru ini akan tumbuh bersama sama dengan tanaman pendahulunya dan akhirnya akan membentuk suatu rumpun dengan banyak buluh bambu bambu berdaun tunggal tersusun berselang seling diujung buluh atau ranting-rantingnya. Berat jenis bambu sekitar 0,6 samapai 0,9 (kering udara) lebih ringan dari air. Meskipun bambu cepat tumbuh namun tetap pada batas maksimumnya, yaitu untuk daerah tropis 6 bulan setelah tunas timbul. Ini merupakan suatu hal yang membedahkan bambu dengan pohon biasa. Bambu ditebang setelah berumur 4 tahun, jumlah bambu per hektar antara 100 - 500 rumpun atau 2000 - 14000 batang, tergantung jenis dan kesuburan tanahnya, sedangkan garis tengahnya antara $2-10 \mathrm{~cm}$. Jenis bambu yang banyak dikenal di indonesia adalah : bambu tali (Apus), bambu Betung, Bambu Talang, bambu Ater, bambu Tutul, bambu Wulung. [3]

Tabel 1. Sifat mekanik bambu Apus [4]

\begin{tabular}{|l|l|}
\hline \multicolumn{1}{|c|}{ Sifat Mekanik } & \multicolumn{1}{c|}{ MPa } \\
\hline Kekuatan tarik & 150 \\
\hline Yield Strength & 53,53 \\
\hline Modulus Elastisitas & 9901,96 \\
\hline Kekuatan tekan & 49,41 \\
\hline Kekuatan geser & 3,872 \\
\hline Kekuatan tarik tegak lurus serat & 2,77 \\
\hline
\end{tabular}

Komposit adalah suatu material yang terbentuk dari kombinasi dua atau lebih material sehingga dihasilkan material komposit yang mempunyai sifat mekanik dan karakteristik yang berbeda dari material pembentuknya. Komposit adalah suatu material yang terbentuk dari kombinasi antara dua atau lebih material pembentuknya melalui 
pencampuran yang homogen. Komposit memiliki sifat mekanik yang lebih bagus dari logam, kekakuan jenis (modulus Young/density) dan kekuatan jenisnya lebih tinggi dari logam. Beberapa lamina komposit dapat ditumpuk dengan arah orientasi serat yang berbeda, gabungan lamina ini disebut sebagai laminat.

Secara umum material komposit tersusun dari dua komponen utama yaitu matrik (bahan pengikat) dan filler (bahan pengisi). Filler adalah bahan pengisi yang digunakan dalam pembuatan komposit, biasanya berupa serat atau serbuk.

Dari pengertian diatas, dapat di simpulkan bahwa komposit adalah bahan yang dibentuk dari dua jenis material yang berbeda, yaitu:

Penguat (reinforcement), yang mempunyai sifat kurang ductile tetapi lebih kaku serta lebih kuat.

Matriks, umumnya lebih ductile tetapi mempunyai kekuatan dan kekakuan yang lebih rendah.[5]

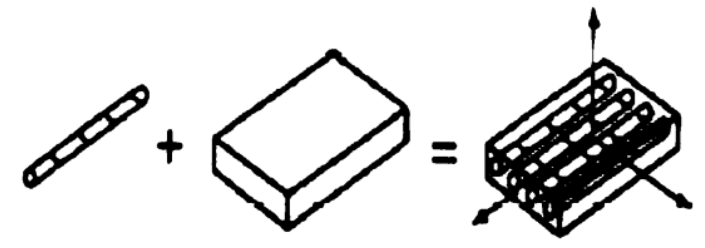

Gambar 1. Fibrous Composites

Matriks adalah fasa dalam komposit yang mempunyai bagian atau fraksi volume terbesar (dominan).

Fungsi matriks

1. Mentransfer tegangan ke serat secara merata.

2. Melindungi serat dari gesekan mekanik.

3. Memegang dan mempertahankan serat pada posisinya.

4. Melindungi dari lingkungan yang merugikan.

\section{Sifat-sifat matriks}

1. Sifat mekanis yang baik.

2. Kekuatan ikatan yang baik.

3. Ketangguhan yang baik.

4. Tahan terhadap temperatur.

Resin poliyester adalah resin yang terbentuk oleh reaksi asam organik dan polyhydric dibasa alkohol. Resin poliyester yang digunakan dalam lembaran cetakan senyawa dan toner dari printer laser. Dinding panel dibuat dari resin polyester diperkuat dengan fiberglass disebut fiberglass diperkuat plstik (FRP). Polyester tak jenuh yang kondensasi polimer yang terbentuk oleh reaksi dari polyols juga dikenal sebagai polyhydric alkohol, senyawa organik dengan beberapa alkohol atau hidroksi fungsional kelompok, dengan jenuh atau tidak jenuh dibasa asam. Dalam penelitian ini, jenis matriks atau perekat yang dipilih adalah jenis Unsaturated Poliyester Resin dengan merek dagang YUKALAC 157 BQTN-EX dengan data teknis sebagai berikut:
1. Masa jenis $(\rho)$
$=1,2$ $\mathrm{g} / \mathrm{cm}^{3}$

2. Kekuatan tarik $(\sigma)$ $\mathrm{N} / \mathrm{mm}^{2}$

3. Modulus elastisitas (E) $1,18.103 \mathrm{~N} / \mathrm{mm}^{2}$

4. Poisson ratio (v)

$$
=12,07
$$$$
=
$$$$
=0,33
$$

Katalis yang digunakan pada penelitian ini adalah katalis komersil/pasaran berupa MEKPO (Metil Etil Katon Peroksida), berfungsi sebagai zat curing, mempersingkat waktu curing.

Serat atau fiber dalam bahan komposit berperan sebagai bagian utama yang menahan beban, sehingga besar kecilnya kekuatan bahan komposit sangat tergantung dari kekuatan serat pembentuknya. Serat terdiri dari dua jenis yaitu, serat alam dan serat sintetis. Serat alam adalah serat yang dapat langsung diperoleh dari alam. Biasanya berupa serat yang dapat langsung diperoleh dari tumbuh-tumbuhan dan binatang. Serat ini telah banyak digunakan oleh manusia diantaranya adalah kapas, wol, sutera, pelepah kelapa sawit, sabut kelapa, ijuk, bambu, nanas dan knaf atau goni. Serat sintetis adalah serat yang dibuat dari bahan-bahan anorganik dengan komposisi kimia tertentu. Serat sintetis yang telah banyak digunakan antara lain serat gelas, serat karbon, kevlar, nylon, dan lain-lain.

Arah serat penguat akan menentukan kekuatan dari komposit, arah serat sesuai dengan arah kekuatan maksimum. Arah serat juga mempengaruhi jumlah serat yang dapat diisikan ke dalam matriks. Semakin cermat 
penataannya, maka akan semakin banyak penguat yang dapat masuk dan akan semakin kuat pula komposit tersebut. Apabila ditata sejajar akan berpeluang sampai $90 \%$, bila separuh dan saling tegak lurus peluangnya $75 \%$, dan dengan tatanan acak hanya berpeluang sekitar 15-50\%. Dan hal tersebut akan menentukan kekuatan optimum dari komposit saat komposit berada dalam keadaan yang maksimum. [2]

\section{Metode Penelitian}

\section{Pemilihan Bambu}

Pada tahap persiapan bahan baku utama di peroleh kesimpulan: makin tipis pembilahan yang dilakukan maka makin cepat proses degumming yang terjadi hal ini terlihat ketika proses pemisahan serat dimana bilahbilah bambu yang tipis mudah untuk lakukan pemisahan seratnya, jika dibandingkan dengan bilah bambu yang tebal. Penggunaan kadar persentase $\mathrm{NaOH}$, dan bambu yang digunakan yakni menggunakan bambu apus.

\section{Tahap Pelunakan}

Tahap pelunakan dimana bambu direbus dengan suhu $70^{\circ} \mathrm{C}$, lama perebusan sangat tergantung dari tebal bilah yang direbus makin tipis bilah maka makin cepat waktu perebusan, tetapi makin tebal bilah maka waktu perebusan akan semakin lama. Jika bilah tipis $(2 \mathrm{~mm})$ direbus terlalu lama akan didapatkan serat bambu yang halus dan mudah putus, demikian juga sebaliknya jika bilah bambu tebal direbus sebentar (3 jam) masih sulit untuk melepaskan ikatan antar serat.

\section{Tahap Pembilasan}

Teknik pembilasan yang diambil adalah pembilasan dengan sistem rendam, dimana proses degumming atau pemecahan zat pengikat serat dilakukan secara perlahan dan menghilangkan kandungan $\mathrm{NaOH}$ yang tersisa secara bertahap.

\section{Tahapan Pemisahan serat}

Pada tahap terakhir merupakan tahapan untuk memisahkan serat-serat bambu untuk memdapatkan serat yang diinginkan, teknik yang terbaik adalah proses pengrollan secara perlahan, bertujuan memicahkan antara zat pengikat serat dengan serat bambu. Teknik pengrollan berbeda dengan pemukulan, jika diroll serat tidak terputus akibat pemukulan yang terlalu keras. Jika dilakukan teknik penekanan secara berulang, kadang-kadang dibeberapa bagian terlewat. Sehingga teknik pemisahan serat yang terbaik adalah dengan pengrollan baik maual ataupun dengan bantuan roll mekanis. Kemudian bambu disisir dengan menggunakan sikat kawat untuk memisahkan seratnya, dan serat yang sudah terpisah dijemur dalam waktu 3 hari, tetapi penjemuran tanpa kontak langsung dengan sinar matahari.

\section{Pembuatan Komposit}

Proses pembuatan komposit serat dari bambu dengan matrik polyester adalah sebagai berikut:

a. Serat yang sudah diekstrat, kemudian direndam dan dicuci dari kotoran dengan air. Serat diangin-anginkan sampai kering ditempat teduh. Serat yang sudah dibersihkan dari kotoran kemudian direndam larutan alkali $\mathrm{NaOH}$ selama 2 jam. Serat kemudian dibilas dengan air bersih, kemudian serat dikeringkan ditempat yang tidak terkena sinar mata hari langsung.

b. Cetakan dibersihkan, kemudian dioleskan wax atau oli secara merata agar komposit tidak menempel pada cetakan.

c. Membuat campuran resin dengan katalis dengan perbandingan 99:1, kemudian diaduk hingga merata selama 4 menit.

d. Langkah berikutnya adalah mengoleskan campuran resin hingga rata.

e. Masukkan serat sesuai perbandingan volume yang telah ditentukan, kemudian tuang resin kembali hingga penuh sambil ditekan-tekan untuk menghindari terjadinya gelembung udara.

f. Pasang tutup cetakan agar permukaan komposit menjadi rata, kemudian diberi beban diatasnya.

g. Biarkan hingga mengering selama \pm 2 jam, kemudian komposit dikeluarkan dari cetakan.

h. Benda uji komposit siap untuk dipotong menjadi spesimen benda uji. 


\section{Pembuatan Cetakan Spesimen}

Bahan yang digunakan untuk cetakan ini adalah kaca, hal ini dikarenakan hasil cetakan lebih mudah dalam pelepasan. Spesimen uji dibuat satu persatu sebanyak 25 buah untuk uji impak dan setelah pengujian di ambil 2 buah dari kekuatan impak yang paling tinggi dan yang paling rendah untuk uji SEM. Adapun standar pengujian yang dilakukan adalah ASTM dengan uji impak menggunakan standar ASTM D256. Agar tidak terjadi kesalahan dalam pembuatan benda uji, maka ukuran cetakan dibuat sedikit lebih besar yaitu 1-5 mm.
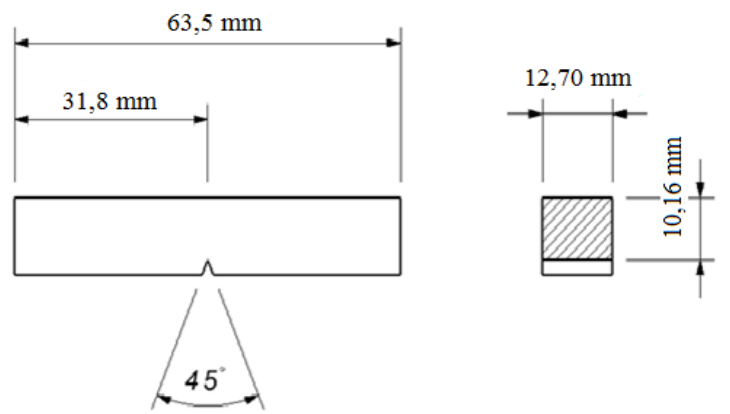

Gambar 2. Spesimen Uji Impak ASTM D256

\section{Hasil dan Pembahasan}

\section{Uji Impak Izod}

Tabel 1 Data Uji Impak Izod

\begin{tabular}{|c|c|c|c|}
\hline No & $\begin{array}{c}\text { Fraksi } \\
\text { Volume Serat } \\
(\%)\end{array}$ & $\begin{array}{l}\text { Kuat Impak } \\
\left(\mathrm{kJ} / \mathrm{m}^{2}\right)\end{array}$ & $\begin{array}{l}\text { Rata-Rata Kekuatan } \\
\text { Impak }\left(\mathrm{kJ} / \mathrm{m}^{2}\right)\end{array}$ \\
\hline \multirow{5}{*}{1.} & \multirow{5}{*}{ 年 } & 3,27 & \multirow{5}{*}{3,28} \\
\hline & & 4,27 & \\
\hline & & 4,48 & \\
\hline & & 2,94 & \\
\hline & & 1,46 & \\
\hline \multirow{5}{*}{2.} & \multirow{5}{*}{10} & 10,61 & \multirow{5}{*}{12,64} \\
\hline & & 13,03 & \\
\hline & & 9,56 & \\
\hline & & 13,93 & \\
\hline & & 14,09 & \\
\hline \multirow{5}{*}{3.} & \multirow{5}{*}{15} & 17,81 & \multirow{5}{*}{18,77} \\
\hline & & 20,18 & \\
\hline & & 21,76 & \\
\hline & & 17,84 & \\
\hline & & 16,24 & \\
\hline \multirow{5}{*}{4.} & \multirow{5}{*}{20} & 26,75 & \multirow{5}{*}{27,44} \\
\hline & & 33,64 & \\
\hline & & 23,27 & \\
\hline & & 23,94 & \\
\hline & & 29,61 & \\
\hline
\end{tabular}

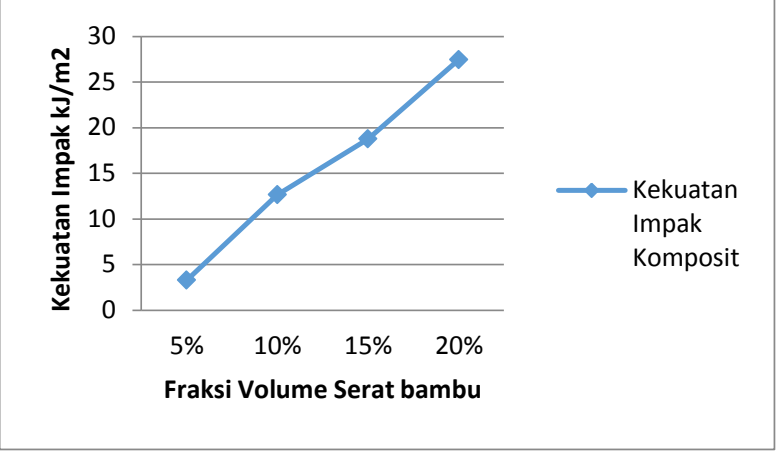

Gambar 3. Grafik nilai kekuatan impak komposit serat bambu

Grafik pada gambar 3. menunjukka bahwa semakin besar fraksi volume serat yang digunakan dalam pembuatan komposit akan meningkatkan kekuatan impaknya. Sehingga dapat lebih maksimal dalam menahan ketangguhan beban pengujian impak.

Dari hasil kekuatan impak komposit serat Bambu yang diperoleh dari penelitian ini, dimana kekuatan impak semakin meningkat seiring bertambahnya fraksi volume serat, maka perlu dilakukan penelitian lebih lanjut mengenai komposit serat bambu dengan fraksi volume yang lebih tinggi.

\section{Pengamatan Secara Mikro Dengan SEM}

Untuk mengetahui mekanisme kegagalan komposit akibat uji impak secara mikro, maka dilakukan pengamatan penampang patahan dengan SEM. Penampang patahan yang diamati adalah sampel uji impak komposit 5\% serat bambu, karena komposit ini memiliki nilai kekuatan impak terendah.

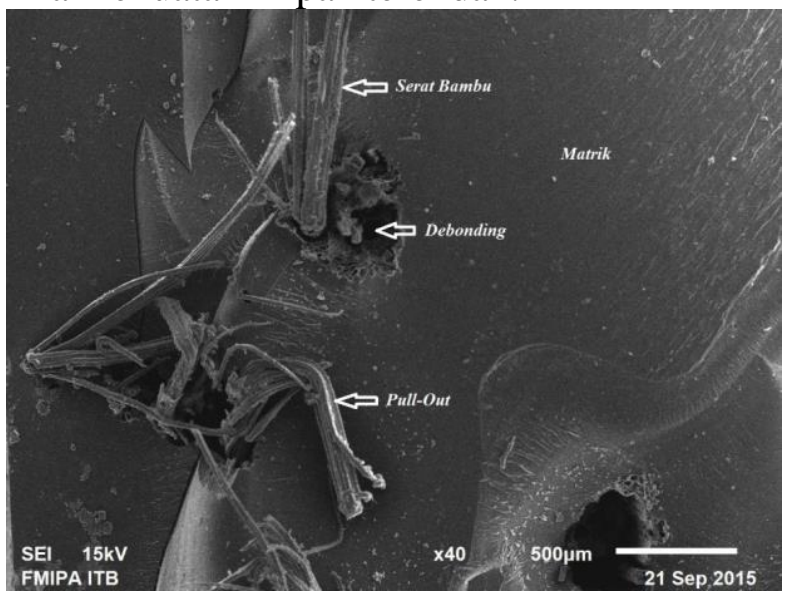

Gambar 4. Penampang patahan komposit 5\% serat bambu setelah diuji impak

Pada penampang patahan komposit masih terlihat pada beberapa titik terjadi kegagalan 
poll-out yang ditunjukan pada gambar 4. pollout disebabkan bonding (daya ikat) antara serat dan matrik yang kurang sempurna sehingga pada saat terjadi pengujian, serat terlepas dari matrik. Yang sehingganya kekuatan impak komposit serat bambu kurang maksimal.

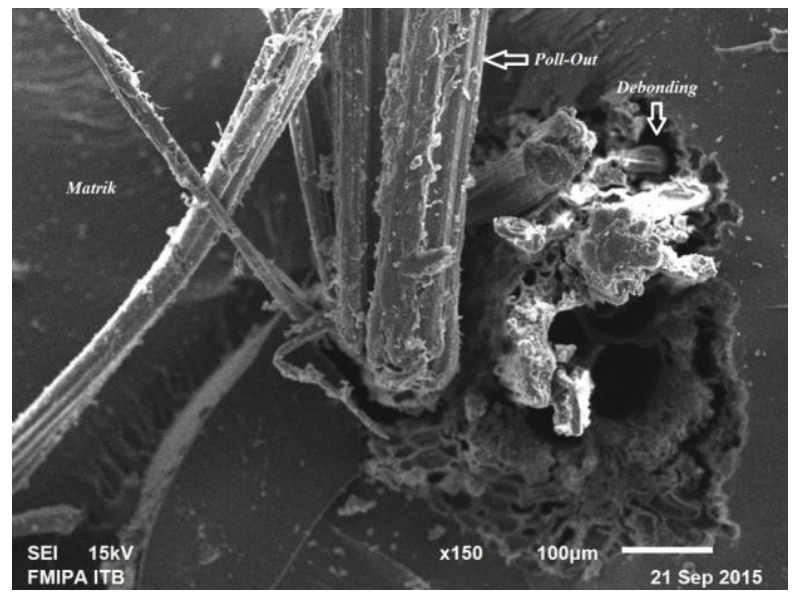

Gambar 5. Penampang patahan komposit 5\% serat bambu setelah diuji impak adanya rongga udara

Pada komposit serat bambu, poll-out kemungkinan terjadi akibat perlakuan alkali yang kurang sempurna pada serat bambu dibagian tersebut. Pada saat ini terjadi pengujian impak, daya ikat yang rendah menyebapkan serat terlepas dari matrik.

Perlakuan alkali pada serat berfungsi menghilangkan minyak dan kotoran yang melekat pada permukaan serat sehingga permukaan serat menjadi kasar. Oleh karnanya, hal ini bisa menjadi perhatian guna mendapatkan kekuatan impak komposit serat bambu yang lebih baik karena poll-out pada komposit serat bambu dapat menurunkan kekuatan impak-nya.

Kemudian penampang patahan yang diamati adalah sampel uji impak komposit $20 \%$ serat bambu, karena komposit ini memeliki nilai kekuatan impak paling tinggi.

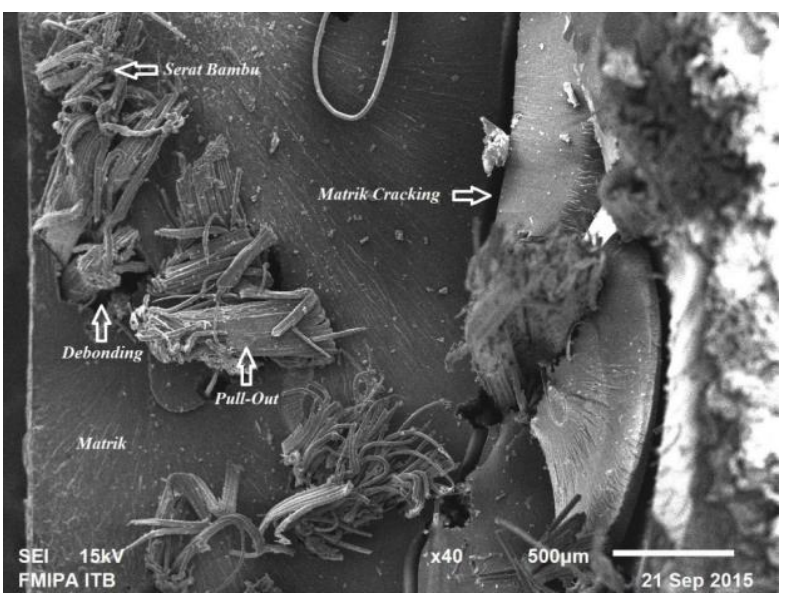

Gambar 6. Matrik cracking pada komposit

$20 \%$ serat bambu setelah diuji impak

Pada spesimen uji impak dari gambar tersebut dijumpai adanya matrik cracking, yaitu retaknya matrik akibat matrik bersifat getas. Hal ini perlu menjadi perhatian karena walaupun sifat getas menyebapkan kekuatan meningkat, namun jika retakan yang terjadi melebihi batas dapat menyebapkan debonding.

Kegetasan suatu matrik dapat dipengaruhi oleh jumlah katalis yang diberikan kepada resin. Pada penelitian ini, jumlah katalis yang diberikan sesuai dengan setandar yang di berikan yakni 99:1 volume resin. Untuk mengetahui pengaruh resin terhadap kekuatan impak, dimungkinkan untuk melakukan penelitian lanjutan mengenai variasi jumlah katalis pada komposit serat bambu.

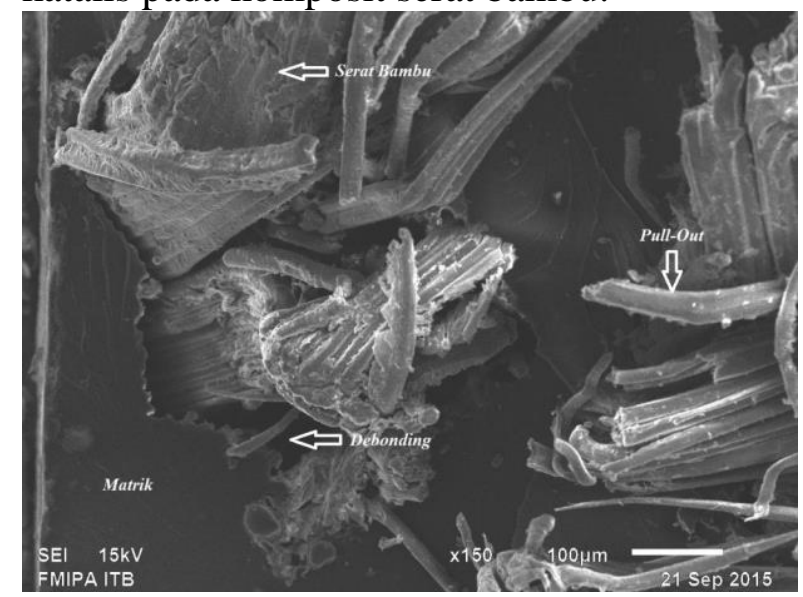

Gambar 7. Rongga antara serat dan matrik pada komposit $20 \%$ serat bambu.

Setelah dilakukan pengamatan SEM ditemukan debonding, yaitu lepasnya daya ikat antara serat dan matrik. Debonding terjadi akibat tidak kuatnya daya ikat antar serat dan matrik sehingga saat terjadi 
pengujian matrik terlepas dari serat. Dari gambar 4.5 dapat dilihat adanya ruang kosong adanya serat dan matrik. Hal ini sangat berpengaruh terhadap kekuatan impak dari komposit.

\section{Kesimpulan}

Berdasarkan beberapa pengujian yang telah dilakukan, maka dapat disimpulkan :

1. Dari pengujian impak maka dapat disimpulkan bahwa untuk uji impak komposit serat bambu dengan komposisi resin $95 \%$ serat $5 \%$ serat didapat hasil kekuatan impak yang paling rendah yaitu $3,28 \mathrm{~kJ} / \mathrm{m}^{2}$ karena pengaruh serat yang terlalu sedikit dan komposisi resin $80 \%$ serat $20 \%$ didapat hasil kekuatan impak yang tertinggi yaitu sebesar $27,44 \mathrm{~kJ} / \mathrm{m}^{2}$.

2. Pada penampang patahan komposit masih terlihat terjadi kegagalan poll-out yang disebabkan bonding (daya ikat) antara serat dan matrik yang kurang sempurna sehingga pada saat terjadi pengujian, serat terlepas dari matrik. Pada spesimen uji impak, dijumpai adanya matrik cracking, yaitu retaknya matrik akibat matrik bersifat getas. Hal ini perlu menjadi perhatian karena jika retakan yang terjadi melebihi batas dapat menyebapkan debonding.

\section{Daftar Pustaka}

[1] Porwanto, A. Daniel, 2010. "Karakterisasi komposit berpenguat serat bambu dan serat gelas sebagai alternatif bahan baku industri”. Jurusan teknik fisika fti ITS. Surabaya.

[2] Purnama, Herry, 2013." Pengaruh jenis serat terhadap kuat tarik dan kuat benturan pada material komposit resin epoksi”. Jurusan teknik kimia, Fakultas Teknik, Universitas Muhammadiyah Surakarta.

[3] Manuputty, Monalisa, 2010. "Pemanfaatan material bambu sebagai alternatif bahan komposit pembuatan kulit kapal pengganti material kayu untuk armada kapal rakyat yang beroperasi di daerah Maluku". Jurnal teknologi. Volume 7 nomor 2; 788 -794.
[4] Nurkertamanda, Denny, 2012, "Desain proses pembentukan serat bambu sebagai bahan dasar produk industri kreatif berbahan dasar serat pada ukm ". Program studi teknik industri. Fakultas Teknik Universitas Diponegoro.

[5] Putradi, G. Ikhsan, 2011. "Kekuatan impak komposit sandwich berpenguat serat aren". Jurusan teknik mesin fakultas teknik universitas sebelas maret, Surakarta. 